\title{
Considerações acerca do contexto ambiental dos sítios arqueológicos do alto rio Uruguai: Projeto Salvamento Arqueológico Uruguai UHE-Itá
}

\author{
Julio Cezar Rubin de Rubin* \\ Mirian Carbonera**
}

\begin{abstract}
RUBIN, J.C.R; CARBONERA, M. Considerações acerca do contexto ambiental dos sítios arqueológicos do alto rio Uruguai: Projeto Salvamento Arqueológico Uruguai UHE-Itá. R. Museu Arq. Etn., São Paulo, n. 21, p. 153-166, 2011.
\end{abstract}

Resumo: Neste texto foram analisados os dados referentes aos aspectos ambientais e os sítios arqueológicos pesquisados durante uma das etapas do Projeto Salvamento Arqueológico Uruguai, realizado entre as décadas de 1980 e 1990. São apresentadas algumas reflexões sobre a dinâmica da área e a ação antrópica, e como esses processos podem ter alterado os sítios até o momento de seu registro. Ressalta-se a importância da relativização das informações coletadas contemporaneamente para evitar interpretações equivocadas.

Palavras-chave: Alto Uruguai - Sítios arqueológicos - Geoarqueologia.

\section{Introdução}

$\mathrm{O}$ presente artigo aborda os sítios arqueológicos registrados na área atingida pela Usina Hidrelétrica de Itá, entre os estados de Santa Catarina e Rio Grande do Sul (Fig. 1). A Usina atingiu seis municípios em Santa Catarina: Itá, Concórdia, Alto Bela Vista, ${ }^{1}$ Peritiba, Ipira e Piratuba e mais quatro municípios no Rio Grande do Sul: Aratiba, Mariano Moro,

(*) Pontifícia Universidade Católica de Goiás/Instituto Goiano de Pré-História e Antropologia. 〈julio.rubin@pq.cnpq.br> (**) Universidade Comunitária da Região de Chapecó/ Centro de Memória do Oeste de Santa Catarina - CEOM. <mirianc@unochapeco.edu.br>

(1) O município de Alto Bela Vista foi criado somente no ano de 1995, quando se desmembrou de Concórdia, portanto, nos relatórios do PSAU-UHE Itá aparece apenas o nome de cinco municípios catarinenses atingidos pela UHE Itá, e não seis.
Severiano de Almeida e Marcelino Ramos. A área escolhida para a construção do eixo da UHE Itá localiza-se entre os municípios de Itá (SC) e Aratiba (RS), justamente na curva denominada Volta do Uvá. O lago atingiu um nível de 370 metros e uma área total de $141 \mathrm{~km}^{2}$. Patrimônios naturais, como o Estreito Augusto César, ${ }^{2}$ e culturais, como é o caso do patrimônio arqueológico, foram submersos pela construção da UHE Itá.

O projeto de salvamento arqueológico foi coordenado pela arqueóloga Marilandi Goulart, que, na área atingida pela UHE Itá,

(2) O Estreito Augusto César, ou simplesmente Estreito do Uruguai, era um canion com 8900 metros de extensão, onde o rio Uruguai que chega a ter mais de $1 \mathrm{~km}$ de largura em alguns pontos, estreitava-se para poucos metros de largura e, em um certo ponto - com apenas sessenta centímetros - permitia que se colocasse um pé em cada margem do rio. 


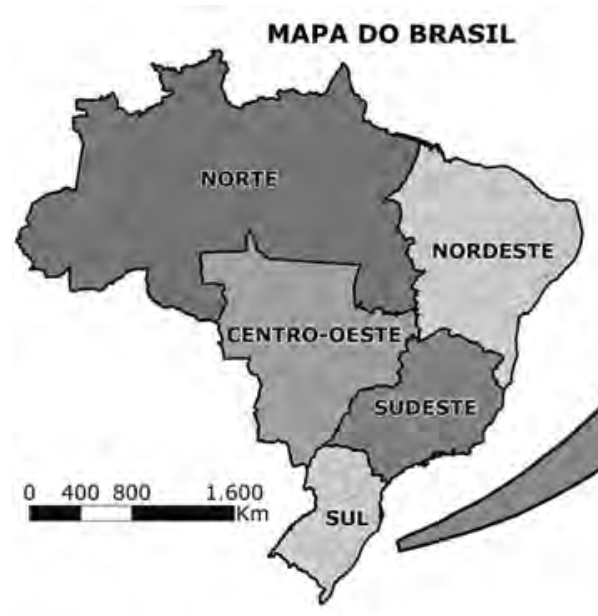

LAPA DA REGIÃO SUL

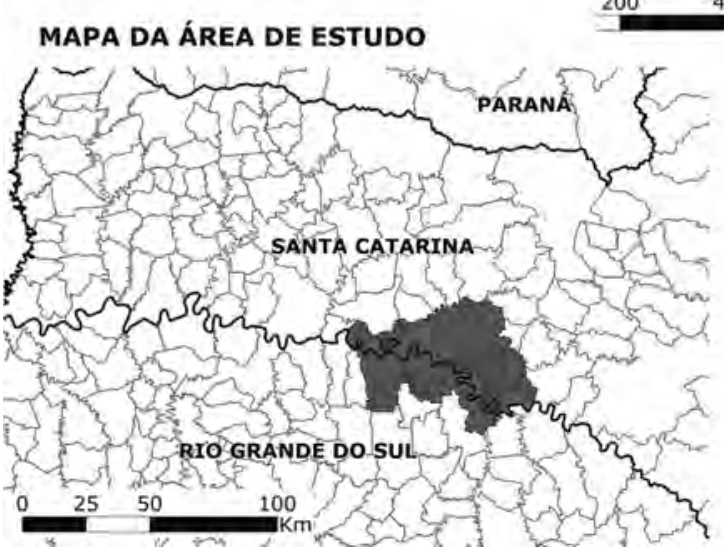

\section{LEGENDA}

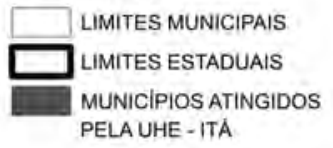

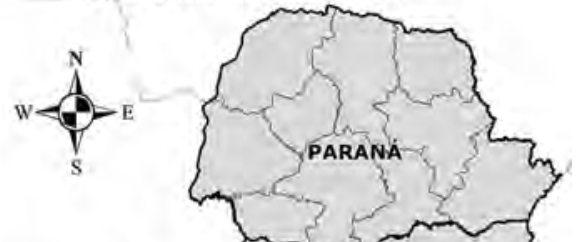

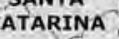

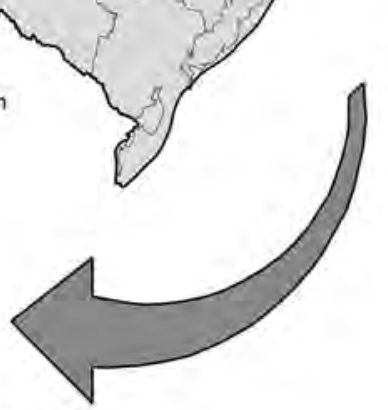

Fig. 1. Localização da Usina Hidrelétrica de Itá.

registrou 201 sítios. ${ }^{3}$ Neste artigo, selecionamos apenas aqueles registrados nas cotas de desvio do rio Uruguai e de enchimento do reservatório, totalizando 167 assentamentos. De acordo com os relatórios ${ }^{4}$ disponíveis, estimamos que

(3) Esse trabalho resultou no "Acervo Marilandi Goulart", que teve origem nas etapas do Projeto Salvamento Arqueológico Uruguai (PSAU). Esse projeto fazia referência às pesquisas de levantamento de sítios arqueológicos, realizadas em todo o trecho nacional do alto rio Uruguai, abrangendo os estados de Santa Catarina e Rio Grande do Sul. Utilizamos a sigla PSAU para nos referirmos ao projeto na fase inicial, na etapa de levantamento de sítios que abrangia desde a formação do rio Uruguai até o município de Itapiranga (na divisa com a Argentina) e PSAU-UHE Itá, para os estudos realizados na área atingida somente por este empreendimento (Carbonera 2008). (4) A área atingida pela UHE Itá foi dividida em quatro trechos a serem sucessivamente estudados, definidos de acordo com a última etapa de campo ocorreu em janeiro e fevereiro de 1996 e, nesse período, os 167 sítios foram reavaliados, constatando-se o estado generalizado de destruição dessas unidades ocupacionais (Goulart 1997a: 99). Os estudos

a concentração de sítios, sendo que: a Área I compreendia basicamente os sítios localizados na área de descaracterização máxima do relevo, atingidos pelo canteiro de obras, construção de estradas, entre outros; as Áreas II, III e IV continham sítios que seriam impactados pelas cotas de desvio do rio e enchimento do reservatório. A primeira etapa de escavações aconteceu em 1986, na Área I, na Volta do Uvá, na margem esquerda do rio Uruguai, foram escavados os seguintes sítios: 251, 252, 253, 254, 255, 256, 257, 258, 259, 260, 261 (Goulart 1988a: 31; Goulart 1997a: 97). Os resultados dessa etapa foram apresentados em relatório parcial, publicado ainda em 1986, o qual não conseguimos localizar. As atividades de 
foram direcionados aos sítios situados na cota de desvio do rio Uruguai (340 metros) e aqueles localizados na área de enchimento do reservatório (370 metros). Além destes, acrescentaram-se mais 13 sítios localizados na faixa de preservação, até a cota de 400 metros, totalizando 167 assentamentos (Goulart 1994: 5). Não encontramos nos relatórios indicação de escavações nessa área, tendo sido realizadas apenas coletas superficiais. Dos 167 assentamentos, foram recuperados aproximadamente 25.856 fragmentos cerâmicos, 2.053 líticos, e observadas 22 manchas de terra preta. Os assentamentos foram assim classificados: 40 pré-cerâmicos, 106 lito-cerâmicos e 21 cerâmicos.

Com este trabalho buscamos realizar uma análise da distribuição dos assentamentos na paisagem por meio de variáveis como: a distribuição dos sítios nas feições geomorfológicas; localização e distância dos sítios em relação às drenagens; fontes de matérias-primas. Além de apresentar os dados, procuramos refletir sobre os resultados dessa pesquisa realizada entre as décadas de 1980 e 1990, incluindo a dinâmica da área, ação antrópica, entre outras.

\section{A distribuição dos sítios pelas feições geomor- fológicas}

No PSAU-UHE Itá a compartimentação regional do relevo foi individualizada em sete feições geomorfológicas: cume, platô, encosta superior, meia encosta, encosta inferior, segundo terraço, primeiro terraço (Fig. 2); segundo Goulart:

campo tiveram continuidade em 1987, na margem direita do rio Uruguai, na Volta do Uvá, município de Itá (SC), onde a ocorrência de sítios semi-intactos implicou um trabalho bem mais lento de escavação, compreendendo os seguintes sítios: 009, 010, 011, 013, 037 (Goulart 1988b: 18; Goulart 1997a: 96). Outras etapas de campo devem ter ocorrido e outros sítios escavados, uma vez que as escavações na área do canteiro da UHE Itá são encerradas em 1989, contudo, por meio da dissertação de Carbonera (2008), constatou-se a falta de alguns relatórios, não sendo possível precisar quantas foram as etapas de escavação e quais são os outros sítios escavados.
Cume - corresponde ao topo da elevação, geralmente de pequenas dimensões, com declividades que se distribuem radial e homogeneamente até o início do platô. Platô - de forma achatada, alongada, com grandes dimensões e declividades que variam de $1^{\circ}$ até $5^{\circ}$, configurando-se numa zona plana e suavizada. Encosta Superior - abaixo do platô, caracterizada pela ruptura da declividade, apresentando-se bastante íngreme, com declividade de $20^{\circ}$ a $30^{\circ}$, atingindo raramente $10^{\circ}$, quando então torna-se mais plana e suavizada. Meia Encosta - zona razoavelmente plana e suavizada, com declividade de $10^{\circ}$ a $15^{\circ}$, sua ocorrência está relacionada com a presença de patamares ao longo da encosta. Em alguns casos, torna-se difícil a individualização destas feições, porque a encosta apresenta-se bastante íngreme ao longo de toda a sua extensão. Encosta Inferior - apresenta as mesmas características da encosta superior, com declividades menos acentuadas próximas ao rio Uruguai, atingindo de $10^{\circ}$ a 15․ 2० Terraço - zonas planas e suavizadas, em nível de 10 a $30 \mathrm{~m}$ acima do rio Uruguai. É composto por sedimentos aluviais e cordões marginais, fazendo parte da sua planície de inundação. Alguns terraços, principalmente aqueles próximos a vertentes de declividade acentuada, possuem características aluvio-coluvionares devido ao aporte de material deslocado das vertentes. $1^{\circ}$ Terraço - corresponde à parte mais baixa, próxima à margem do rio, onde ocorre a construção de bancos arenosos e de depósitos de cascalhos. É de pequena dimensão e facilmente coberto pelas águas em épocas de cheias (Goulart 1997b: 41-42).

Ao distribuirmos os 167 assentamentos pelas feições geomorfológicas (Gráfico 1), observamos que os sítios encontram-se principalmente nas áreas de segundo terraço, meia encosta e encosta inferior, que juntas concen- 


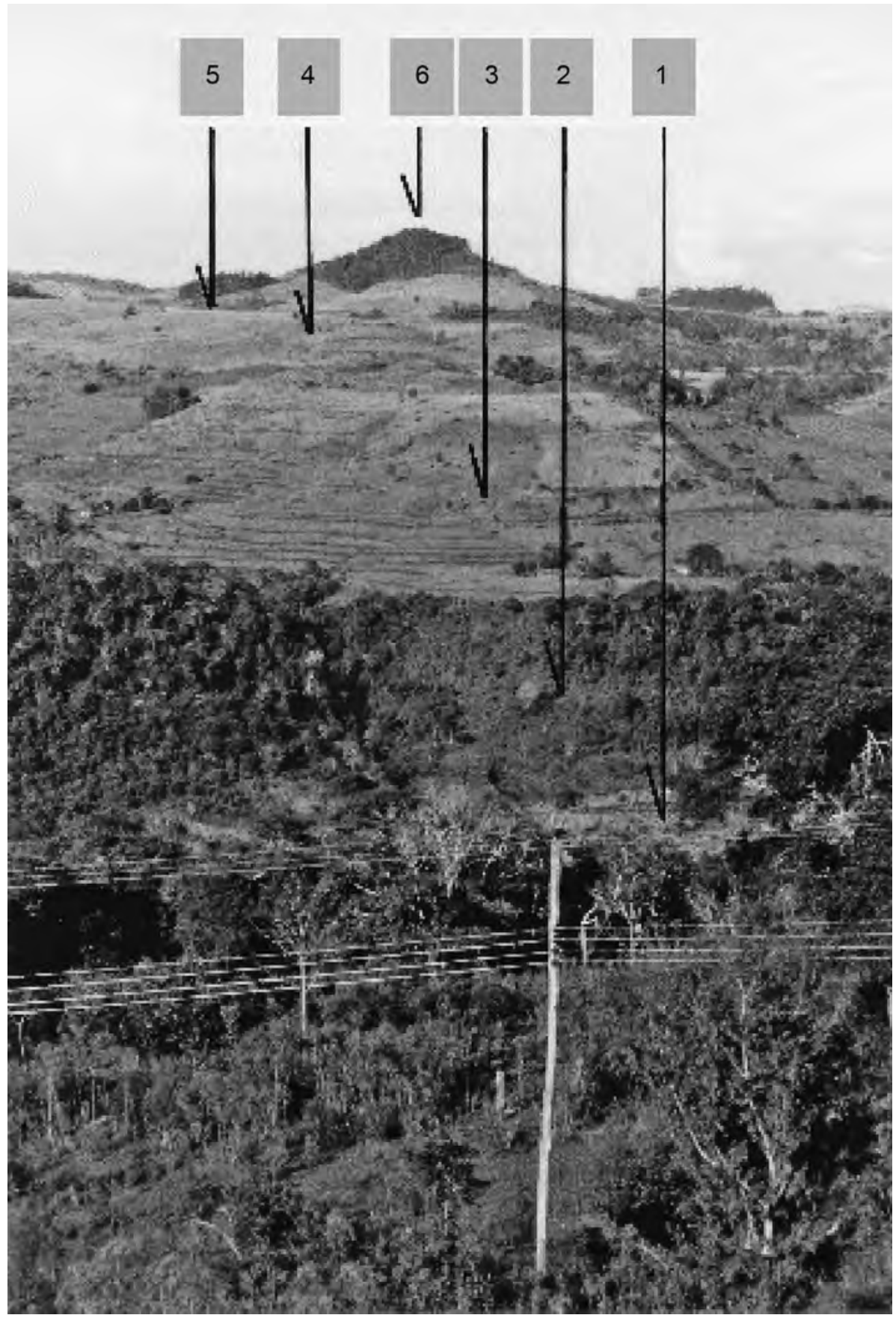

Fig. 2. A partir do rio Uruguai (parte inferior da foto), ocorre a sequência do $2^{\circ}$ terraço (seta 1 ), encosta inferior (seta 2), meia encosta (seta 3), encosta superior (seta 4), platô (seta 5) e cume (seta 6). Não é observado, no local, o 1º terraço. Fonte: Goulart (1997b).

tram 93,41\% dos assentamentos localizados. Já as áreas de encosta superior, platô e feição indefinida apresentam apenas $6,59 \%$ do total de sítios localizados. As únicas feições nas quais não foram encontrados assentamentos são o primeiro terraço e o cume. 


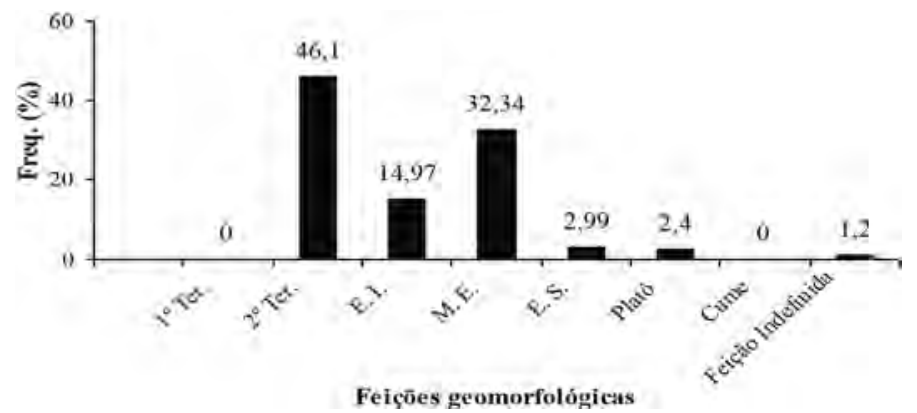

Gráfico 1. Distribuição dos 167 sítios arqueológicos analisados, pelas sete feições geomorfológicas: primeiro terraço (1 Ter.); segundo terraço (2 Ter.); encosta inferior (E.I.); meia encosta (M.E.); encosta superior (E.S.), platô, cume.

\section{Observa-se nenhuma ocorrência no} primeiro terraço, por ser localizado muito próximo ao rio Uruguai, área facilmente inundável, o que não significa que o local não tenha sido ocupado. Também o cume possui o mesmo número de frequência, como corresponde à parte mais alta do relevo, dificilmente seria usado para assentamento por estar distante da maior drenagem, o rio Uruguai, que fornecia água, peixes, entre outros elementos necessários aos grupos humanos que ali se instalaram. Ao contrário, no segundo terraço e meia encosta, têm-se áreas normalmente planas e com declividades baixas, que podiam ser usadas para a construção das casas, bem como para as atividades agrícolas.

Deve-se considerar que em algumas oportunidades foram encontrados fragmentos de cerâmica esparsos no cume, considerados como ocorrências isoladas pela quantidade reduzida e ausência de estruturas arqueológicas. Este fato permite levantar a hipótese de ocupações rápidas, como, por exemplo, relacionadas a atividades de caça ou como local de observação, uma vez que permitia um ótimo campo de visão da região.

Com base nas porcentagens apresentadas e na compartimentação geomorfológica, podemos tecer algumas reflexões. Em primeiro lugar, a distribuição dos sítios arqueológicos nas sete feições geomorfológicas deve ser analisada levando-se em consideração a dinâmica superficial da área, envolvendo principalmente escoamentos laminar e linear, ${ }^{5}$ favorecidos pelas precipitações pluviométricas elevadas, acarretando uma alta erosividade, além da ação antrópica. Como a área foi utilizada de forma intensa desde pelo menos a década de 1950 , acarretando o aparecimento principalmente, de feições erosivas de pequeno porte (sulcos e calhas) e grande porte (ravinas e voçorocas), além das perdas de solos, deve-se considerar o transporte dos vestígios culturais pelas vertentes, do platô ao $1^{\circ}$ terraço. A respeito deste tema, Rubin e Silva (2004) fazem algumas considerações sobre sítios arqueológicos e a dinâmica das vertentes.

Desta maneira, os fatores mencionados podem ter impactado, destruído ou redistribuído os vestígios culturais e, consequentemente, permitindo interpretações equivocadas quanto à localização dos sítios arqueológicos. Por outro lado, a presença de vestígios culturais nas encostas inferior e superior, por exemplo, pode estar relacionada ao fato de que "próximo às aldeias havia áreas de caça, pesca, cultivo, coleta de fontes de matérias primas" (Noelli 1996: 35). Estas considerações estão relacionadas com aqueles sítios que não apresentam associação terra preta/vestígios culturais.

O vale do rio Uruguai apresenta segmentos encaixados que não permitem a migração do canal, onde os terraços são estreitos e segmentos onde o canal migra lateralmente, principalmente nas curvas, remodelando os depósitos associados, evidenciado pela presença de terraços bem estruturados e testemunhos de terraços erodidos, alguns com vestígios culturais associados. Em alguns perfis o $1^{\circ}$ terraço apresentou-se

(5) O escoamento laminar caracteriza-se por um fluxo superficial não concentrado, que retira finas camadas de solo uniformemente. $\mathrm{O}$ escoamento linear origina-se do escoamento superficial, favorecido pela ação da erosão laminar, que retira os sedimentos mais finos, expondo ainda mais os sedimentos grossos, fato que favorece a formação de uma superfície irregular (Lima 1999). 
Considerações acerca do contexto ambiental dos sítios arqueológicos do alto rio Uruguai: Projeto Salvamento Arqueológico Uruguai UHE-Itá.

R. Museu Arq. Etn., São Paulo, n. 21, p. 153-166, 2011.

semelhante à base do $2^{\circ}$ terraço, permitindo aventar a hipótese de que a migração do canal possa ter erodido este último, ou de deposição sobre aquele.

De acordo com a compartimentação geomorfológica, os sítios estão distribuídos em duas unidades distintas, com dinâmicas próprias e já mencionadas: encostas e planície aluvial. Entretanto, em algumas áreas apresentam-se depósitos sobrepostos/associados, identificados como alúvio-coluviais (mencionados na descrição das feições geomorfológicas), cuja relação não foi explorada, principalmente nos sítios em terraços ou na base das vertentes. A Fig. 3 apresenta parte da compartimentação geomorfológica do vale do rio Uruguai próximo à cidade de Itá, onde é possível identificar algumas unidades que estruturam o Planalto Dissecado do rio Iguaçu/rio Uruguai, e que permite visualizar a complexidade da dinâmica superficial envolvendo principalmente solos in situ e transportados com sítios arqueológicos.

\section{Localização dos sítios em relação às redes de drenagem}

Os recursos hídricos disponíveis em uma região são importantes para a escolha do local onde será estabelecido um assentamento, uma vez que a disponibilidade de recursos faunísticos, florísticos e de matérias-primas está diretamente relacionada às redes de drenagem existentes. Para classificação das principais drenagens, Marilandi Goulart adotou a classificação de Horton (apud Christofoletti 1980), que considera canais de $1^{\text {a }}$ ordem aqueles que não possuem tributários; de 2a ordem, os que só recebem tributários de $1^{\text {a }}$ ordem; os de $3^{\text {a }}$ ordem, que recebem tributários de $2^{\mathrm{a}}$ ordem e de $1^{a}$ ordem; $4^{a}$ ordem recebem tributários de $3^{a}$ ordem e também de ordem inferior e assim por diante (Goulart 1997b: 43). Deve-se ressaltar que esta classificação não possui relação com a vazão dos canais.

Dos sítios analisados neste trabalho, observou-se maior ocorrência nas proximidades do rio Uruguai, considerado de $5^{\mathrm{a}}$ ordem. O Gráfico 2 apresenta a distribuição dos 167 sítios em relação às drenagens. Nela, verifica-se que 77 sítios, perfazendo 46,1\%, estavam localizados próximos à drenagem de 5 a ordem; outros 55 sítios, que correspondem a $32,95 \%$, estavam próximos às drenagens de $1^{\circ}$ ordem; 17 sítios, equivalentes a $10,18 \%$, estão próximos às drenagens de $4^{\mathrm{a}}$ ordem (rio do Peixe); 13 sítios, perfazendo $7,78 \%$, estão próximos às drenagens de $2^{\mathrm{a}}$ ordem e, apenas cinco sítios, que são $2,99 \%$, estão assentados próximos às drenagens de $3^{a}$ ordem. Nas proximidades das drenagens de $5^{\mathrm{a}}$ e $4^{\mathrm{a}}$ ordem, que compreendem os maiores rios - Uruguai e do Peixe - da área analisada, estavam $56,28 \%$ do total de sítios analisados (Gráfico 2 e Fig. 4).

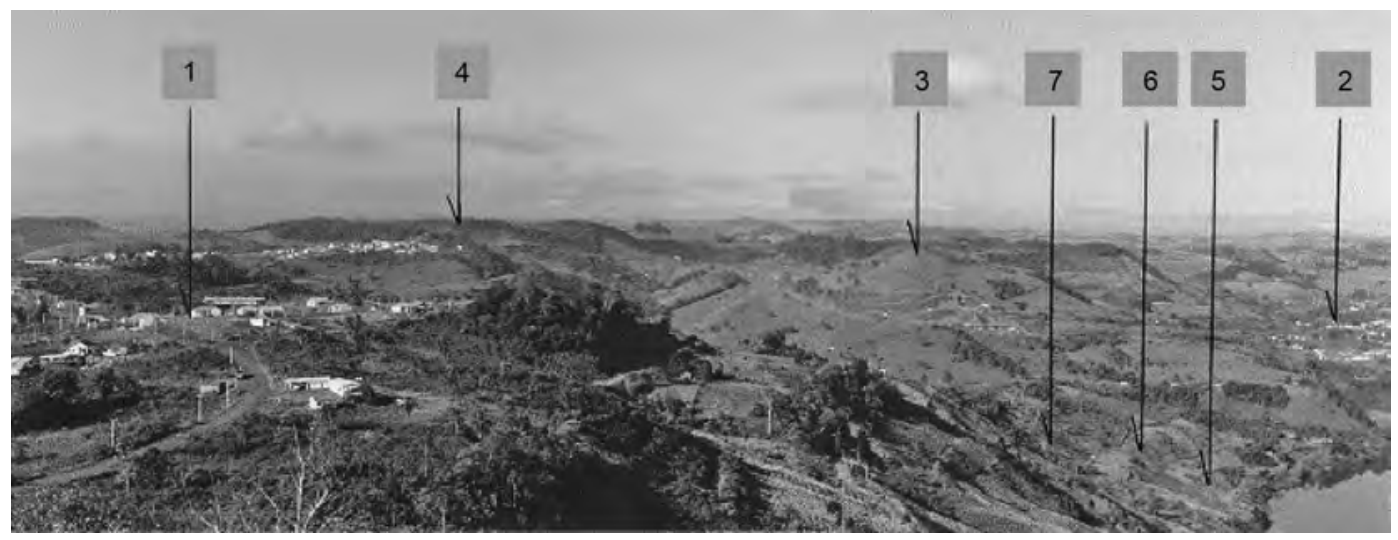

Fig. 3. (1) Nova Itá; (2) Itá Velha; (3) topos convexos a aplanados; (4) platôs bem desenvolvidos e alongados; (5) encosta inferior; (6) meia encosta; (7) encosta superior.

Fonte: Goulart (1997a). 


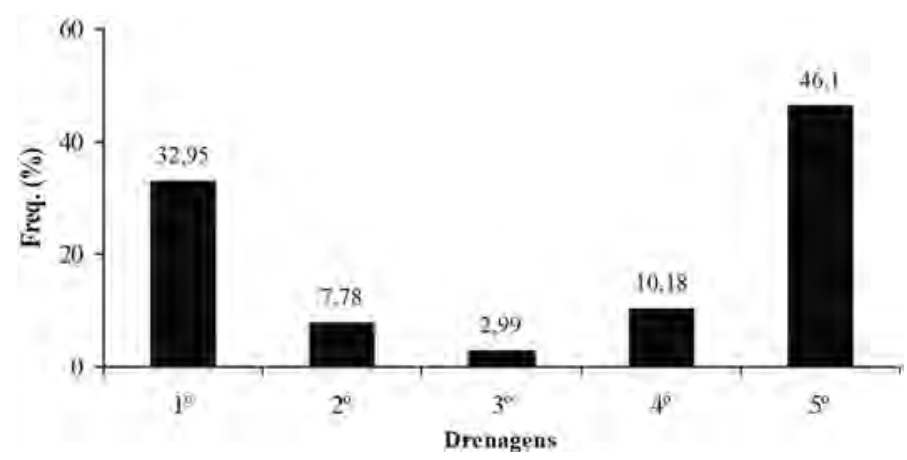

Gráfico 2. Localização dos 167 sítios analisados em relação às cinco principais redes de drenagem.

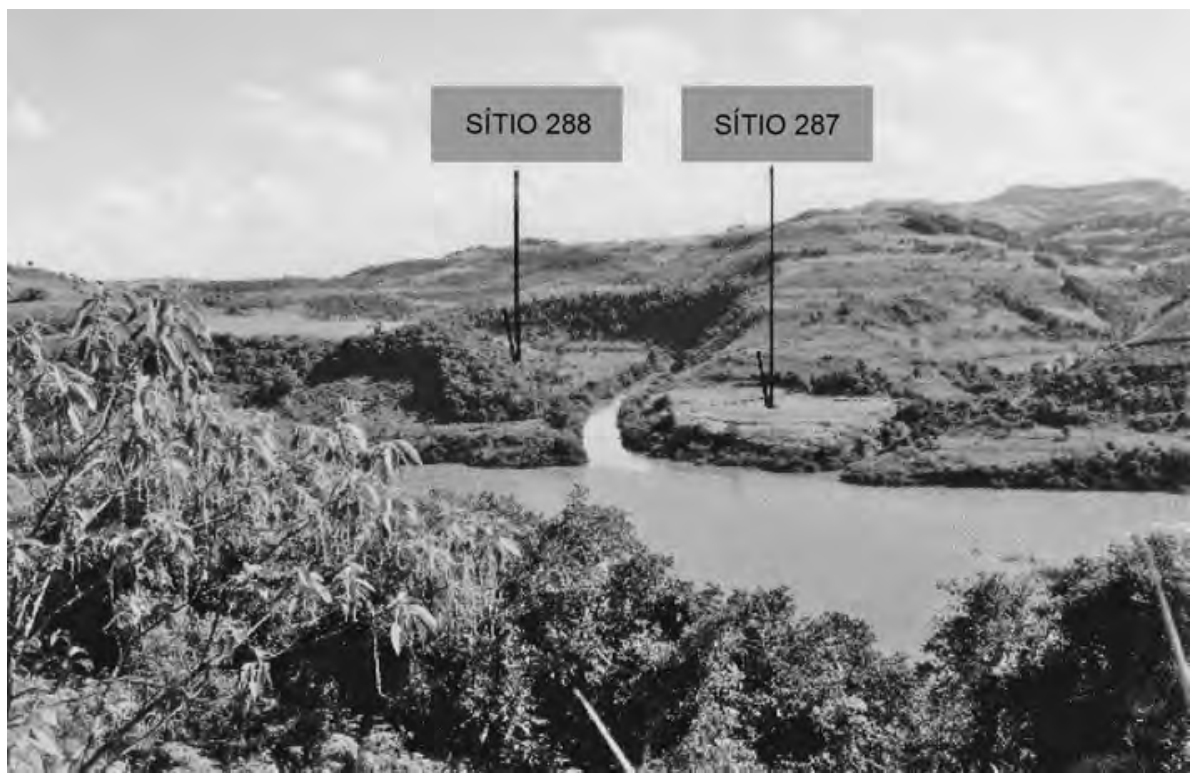

Fig. 4. Implantação dos sítios 287 e 288, junto aos rios Uruguai, do Peixe e afluente de 3a ordem. Fonte: Goulart (1997a).

Outro dado obtido foi a distância dos sítios em relação às drenagens mais próximas. Conforme Goulart (1997b: 48), a distância foi medida em metros, a partir do centro do sítio, considerando a distância obtida da parte central da área de distribuição do material até a drenagem mais próxima. O Gráfico 3 apresenta as distâncias entre as drenagens e os 167 assentamentos: na distância de 10 a 90 metros, ocorre a grande maioria com 114 sítios, perfazendo 68,25\%; entre 100 e 190 metros, estão quarenta sítios, correspondendo a 23,95\%; entre 200 e 290 metros ocorrem oito sítios, representando 4,8\%; de 300 a 390 metros, estão quatro sítios, que somam 2,4\%; entre 400 e $490 \mathrm{~m}$, apenas 1 sítio, que correspondem a $0,6 \%$. Nota-se, a partir dos 167 assentamentos, que a distância do manancial mais próximo até o sítio varia de 10 e mais de 490 metros, predominando a de 10 a 190 metros, com 92,20\% dos sítios analisados.

Os dados relacionados à ordenação e à distância das drenagens também devem ser analisados com precaução, uma vez que se fundamentam nas características atuais das drenagens, que podem ter sofrido profundas alterações em relação ao período de ocupação por parte das 


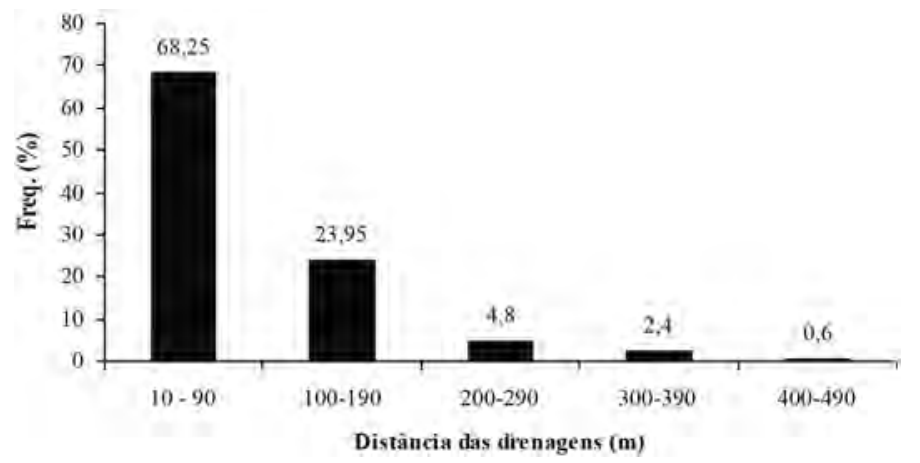

Gráfico 3. Distância entre os 167 sítios analisados em relação às principais drenagens. mapeados, no mínimo, três pontos de exposição de rocha, cada um deles com descrições detalhadas, geralmente trazendo informações sobre localização, tamanho, distância, tipo de rocha, entre outros. Para este trabalho, os dados sobre os recursos litológicos dos sítios da área do reservatório foram compilados e, em seguida, cruzados, para demonstrar a frequência dos pontos de exposição. No Gráfico 4 observa-

populações em questão, como, por exemplo, em decorrência da variação na vazão ou do traçado dos canais.

Fontes de recursos às indústrias lítica e cerâmica

As principais fontes de matérias-primas, como as rochas e os argilominerais, utilizadas para a fabricação dos artefatos líticos e cerâmicos, respectivamente, são encontradas, segundo Goulart:

Amplamente expostos em afloramentos próximos aos sítios, em ocorrências rochosas ou ao longo das cascalheiras das praias do rio Uruguai, assim como nos depósitos de materiais areno-síltico-argilosos encontrados ao longo das planícies de inundação das principais drenagens, gerados pela deposição das correntezas durante as épocas de cheias (Goulart 1997b: 48).

Quanto aos afloramentos de rocha localizados próximos aos sítios (Fig. 5), Marilandi Goulart organizou da seguinte forma: em todos os sítios nota-se que foram

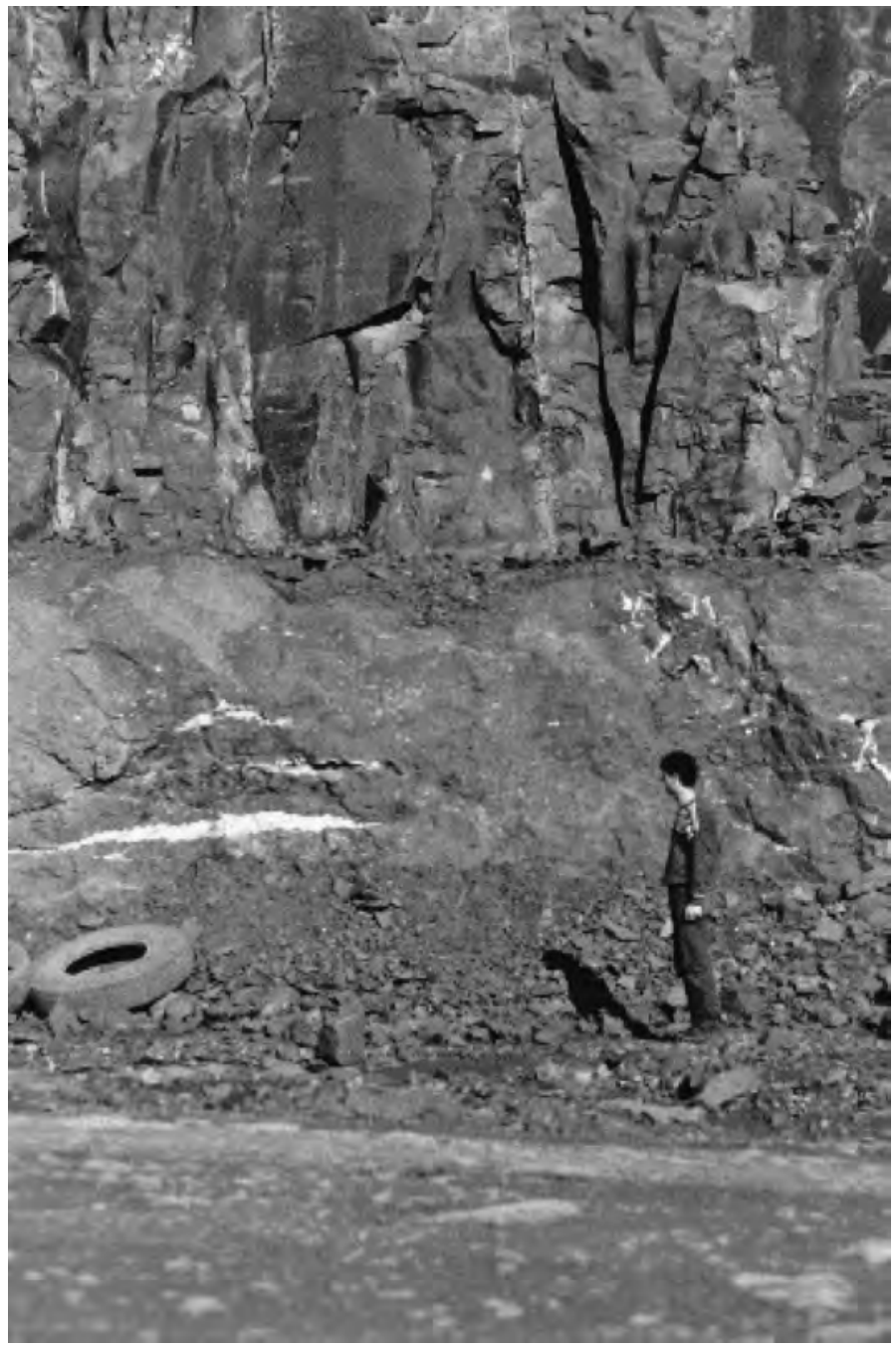

Fig. 5. Afloramento de basalto com presença de níveis de siltito, argilito e brechas presentes entre os diferentes derrames de lavas. Fonte: Goulart (1997a). 


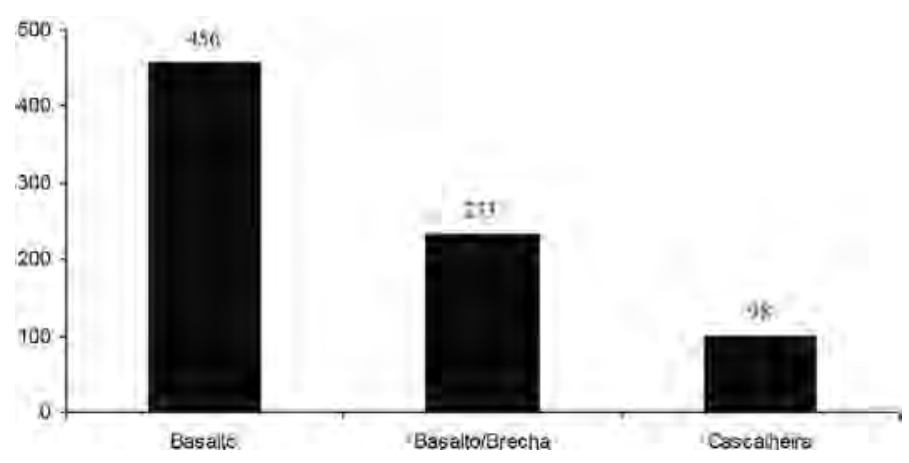

Gráfico 4. Tipos de litologias mais frequentes.

mos que, para os afloramentos de basalto, foram registradas aproximadamente 456 ocorrências, o basalto/brecha ${ }^{6}$ apareceu 233 vezes e, por fim, as cascalheiras, com 98 ocorrências.

Os afloramentos de basalto que ocorrem com mais frequência constituíram-se como fonte de captação de recursos para a confecção de objetos líticos. Por outro lado, as cascalheiras (Figs. 6 e 7) do rio Uruguai são constituídas por uma variedade de grânulos, seixos, blocos e, em alguns casos, matacões de rochosos e minerais como: quartzo, ágata, calcedônia, brechas basálticas, basaltos, entre outros; constituíram-se na grande área de captação de recursos geológicos para o desenvolvimento da indústria lítica das culturas pretéritas (Goulart 1997b: 125).

As cascalheiras localizadas nas margens convexas estão relacionadas com a dinâmica atual do rio Uruguai, canal com índice de sinuosidade compatível com rios Meandrantes, ${ }^{7}$ mas que não apresenta as demais características que definem o sistema. Rubin et al. (2003)

(6) Brechas basálticas (ou brechas basálticas/sedimentares) com limites irregulares surgem com frequência nas zonas de contatos interderrames, refletindo os processos atuantes no intervalo entre as pulsações de extravasamento das lavas basálticas (Goulart 1997b: 32). Os sedimentos finos (silte e argila) que envolvem os fragmentos de rochas, pela alta temperatura dos derrames, resultaram em uma matéria-prima de excelente qualidade para o lascamento.

(7) Rio de canal único com índice de sinuosidade (relação comprimento do canal/comprimento do vale) superior a 1,5 , onde predomina o transporte de carga em suspensão. A migração lateral dos canais ocorre por meio da erosão progressiva das margens côncavas e sedimentação nos leitos convexos dos meandros (Riccomini et al. 2001: 209). estabelecem uma série de considerações sobre a pesquisa arqueológica em ambientes fluviais.

$\mathrm{Na}$ associação das cascalheiras com os sítios arqueológicos, deve ser ressaltado que elas podem não ser contemporâneas aos sítios, uma vez que a dinâmica do rio poderia ser diferente da atual, principalmente em relação à vazão (com reflexos na capacidade de transporte) e no traçado do canal.

Esta correlação é dificultada pela falta de datações para os sítios arqueológicos e de uma abordagem paleoambiental envolvendo diretamente o rio Uruguai. Nestas cascalheiras foram encontrados vestígios culturais cerâmicos e líticos que poderiam perfeitamente estar relacionados com sítios arqueológicos localizados a montante.

Deve-se mencionar que o vale do rio Uruguai, na região, foi modelado por processos de geomorfogênese, além de eventos neotectônicos, sobre diferentes derrames de basalto sobrepostos, com características próprias e distribuição horizontal, o que proporcionou um controle vertical na obtenção das diferentes matérias-primas. Desta forma, quase todos os sítios teriam, nas proximidades, afloramentos de rochas diferentes para explorar, do platô à encosta inferior (Figs. 8 e 9).

Nas áreas com declividades suaves afloram predominantemente basaltos com diáclases horizontais e basalto vesicular e amigdaloidal, onde a retenção da água favorece a decomposição da rocha e desenvolvimento da vegetação. Nos paredões com declividade, geralmente de $90^{\circ}$, predomina basalto com diáclases verticais, onde ocorre disjunção colunar (Leinz; Amaral 1980), ótima fonte de matéria-prima para confecção de mãos-de-pilão. 
Considerações acerca do contexto ambiental dos sítios arqueológicos do alto rio Uruguai: Projeto Salvamento Arqueológico Uruguai UHE-Itá.

R. Museu Arq. Etn., São Paulo, n. 21, p. 153-166, 2011.

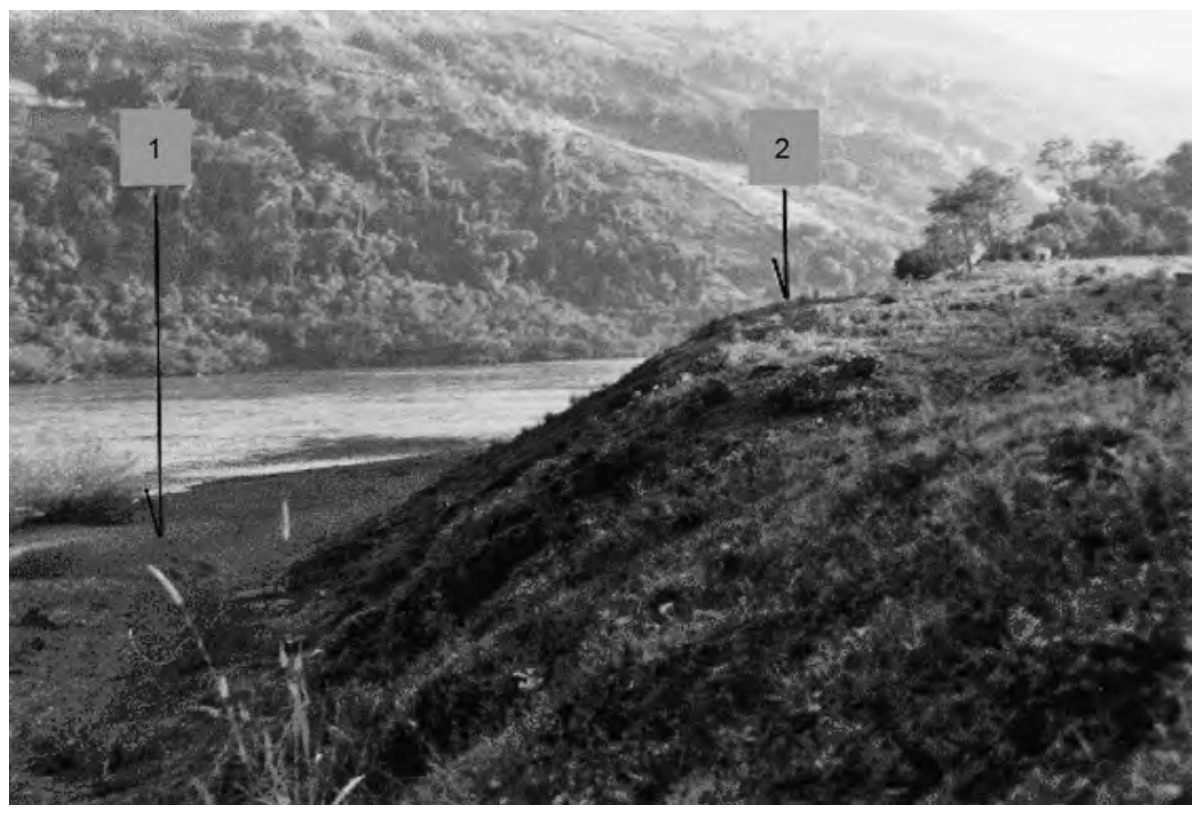

Fig. 6. Cascalheira (seta 1) formada pelo acúmulo de material transportado pelo rio e à direita da foto, uma feição geomorfológica correspondente ao 20 terraço (seta 2), depósito este proveniente da encosta ou formado pela planície de inundação do rio. Fonte: Goulart (1997b).

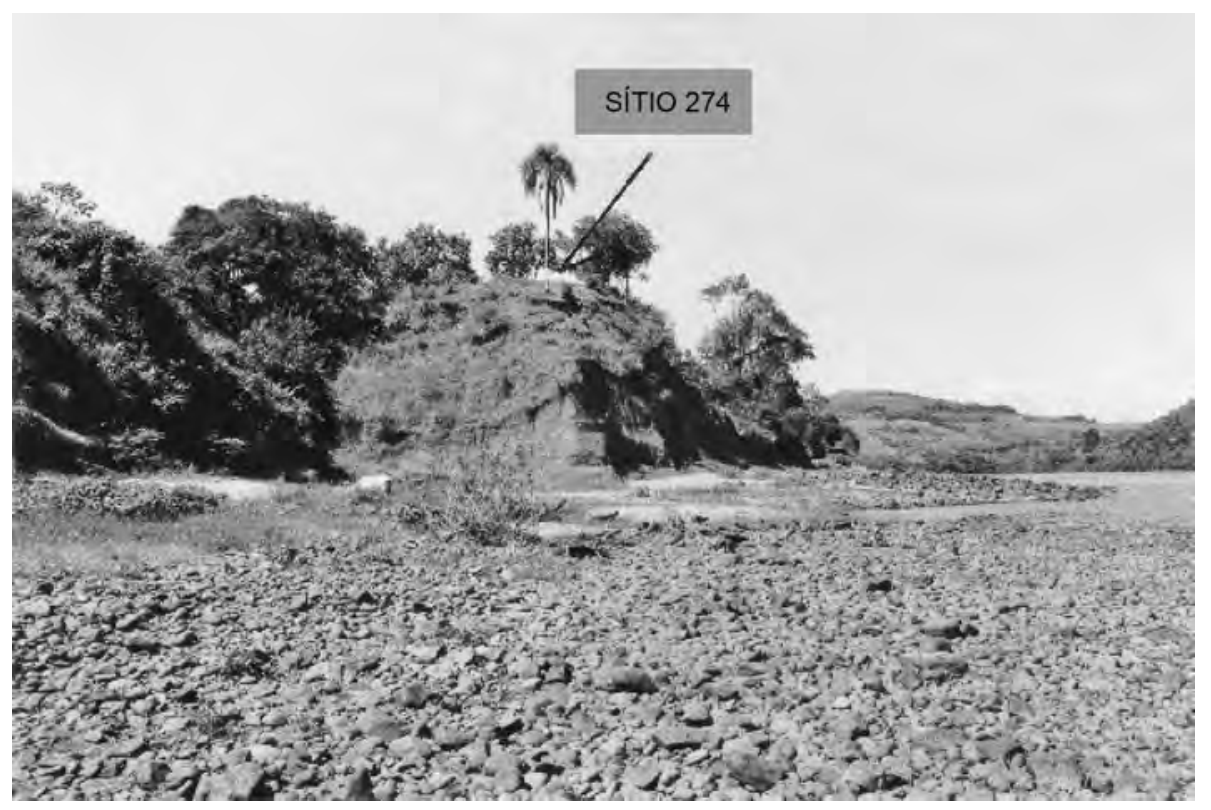

Fig. 7. Cascalheira junto à margem erosiva (esquerda) do rio Uruguai. Fonte: Goulart (1997a). 


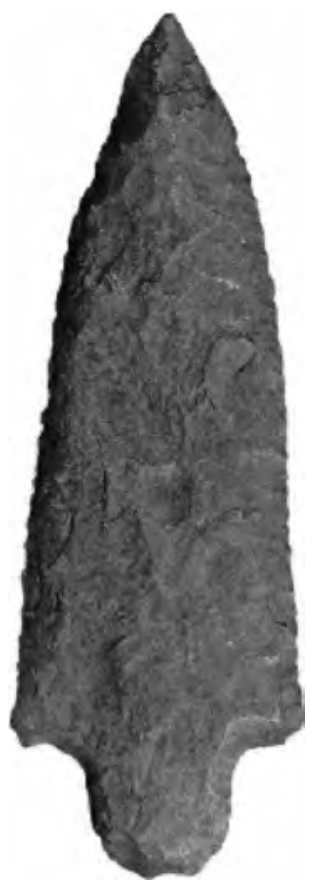

Fig. 8. Ponta de projétil em siltito.

Fonte: Goulart (1997a).

\section{Considerações finais}

O trabalho de descrição do ambiente e inserção dos sítios não é prática recente. No caso do PSAU e do PSAU-UHE Itá, está ligado à concepção teórica e metodológica da coordenadora Marilandi Goulart, que foi orientanda de Luciana Pallestrini, sendo que esta, ainda na década de 1960, criou o Projeto Paranapanema, no estado de São Paulo. Com esse trabalho, também foi uma das pioneiras a privilegiar dados de ordem geoambiental no Brasil (Pallestrini 1975: 13).

Se por um lado os dados do meio ambiente podem auxiliar no entendimento das escolhas feitas pelos grupos humanos pré-coloniais, na compreensão dos locais onde eram desenvolvidas suas atividades cotidianas, como: morar, fabricar utensílios, plantar, captar fontes de matérias-primas, entre outras, por outro lado, não podemos deixar de mencionar os fatores de ordem cultural e a dinâmica ocorrida na área, desde o abandono do local pelas populações pré-coloniais até o momento do registro

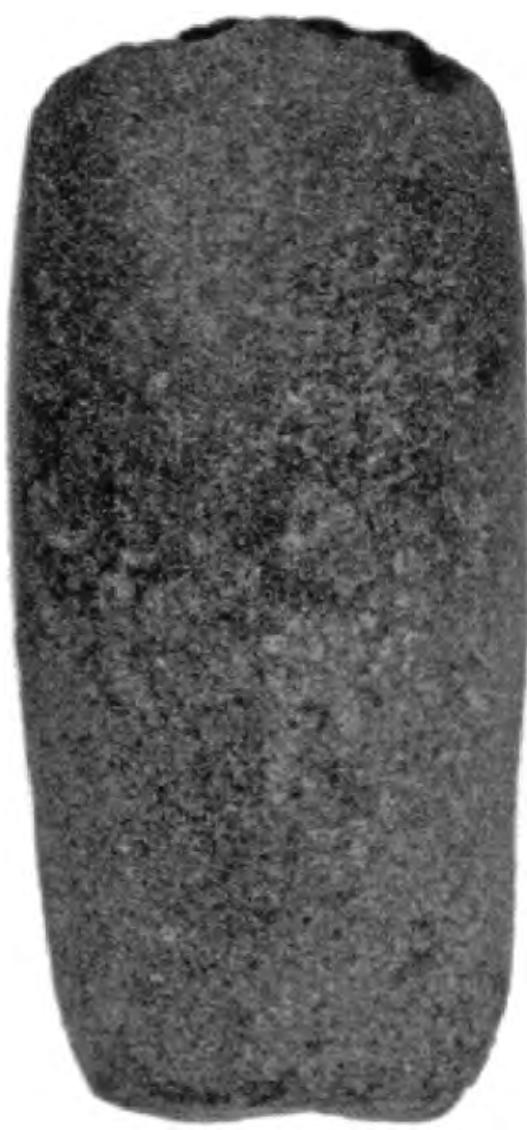

Fig. 9. Lâmina de machado polida em basalto. Fonte: Goulart (1997a).

do sítio. Como vimos, os dados sobre o meio ambiente obtidos por arqueólogos no presente precisam ser relativizados, uma vez que a área, além de sofrer com alterações antrópicas, também passa por modificações naturais.

No caso dos sítios do PSAU e do PSAU-

-UHE Itá, havia uma sistematização para a obtenção das informações básicas sobre a implantação dos sítios (compartimentação geomorfológica) e de captação de recursos, principalmente água, argilominerais e minerais/rochas. Envolvia, basicamente, a identificação da área de dispersão dos vestígios culturais ou delimitação das manchas de terra preta, e a partir do ponto central destas eram realizados caminhamentos no sentido dos quatro quadrantes ou, caso necessário, em sentidos intermediários, utilizando-se ortofotocartas na escala 1:10.000. O campo de visão também 
Considerações acerca do contexto ambiental dos sítios arqueológicos do alto rio Uruguai: Projeto Salvamento Arqueológico Uruguai UHE-Itá.

R. Museu Arq. Etn., São Paulo, n. 21, p. 153-166, 2011.

era descrito a partir do ponto central. Porém, as questões relacionadas com a dinâmica da área, principalmente em relação ao escoamento superficial, processos erosivos e perdas de solos, além de dinâmica fluvial e paleoambiente, ficaram em segundo plano ou não foram abordados, fato que gerou uma lacuna no conhecimento relacionado ao contexto ambiental dos sítios. Deve-se mencionar também que os trabalhos de caracterização do campo de visão, a partir do centro dos sítios, refletem bem a condução da pesquisa, sempre alicerçada no ambiente atual.

Na reavaliação de alguns sítios, realizada em 1996, constatou-se que as ações antrópica e dinâmica da área destruíram completamente algumas manchas pretas, identificadas na meia encosta em etapas de pesquisa realizadas em 1989/90 (Figs. 10 e 11), distribuindo os vestígios culturais na encosta inferior, fato que ilustra muito bem a necessidade de relativizar os dados ambientais atuais, mas que são indispensáveis para a compreensão dos processos modeladores da paisagem e suas relações com os sítios. Esta realidade demonstra que também a observação de Noelli (1996) deve ser relativizada quando da ausência de estruturas.
Como mencionado, a orientação do projeto seguiu, em parte, os procedimentos adotados por Pallestrini no Projeto Paranapanema, mas também apresenta reflexos da diversidade de profissionais que trabalharam com as variáveis ambientais, sem que houvesse uma continuidade na linha de abordagem, fato que teve repercussão na contextualização dos sítios arqueológicos e ambiente. Por outro lado, esta diversidade colocou à disposição diferentes visões desta relação, ressaltando a necessidade da multi e interdisciplinaridade.

As considerações apresentadas e discutidas neste texto permitem estabelecer uma série de conclusões e reflexões, seja pelo detalhamento de algumas como compartimentação geomorfológica, descrição de afloramentos e distâncias das drenagens, seja pelas lacunas e ausências de outras, como aspectos paleoambientais e dinâmica superficial. Acima de tudo, permite fazer uma reflexão envolvendo procedimentos metodológicos desenvolvidos entre as décadas de 1960 e 1970, aplicados em um projeto de pesquisa executado nas duas décadas posteriores com vistoria de campo em 1996 e relatórios finais de 1997, analisados com os conhecimentos disponíveis no final de 2010.

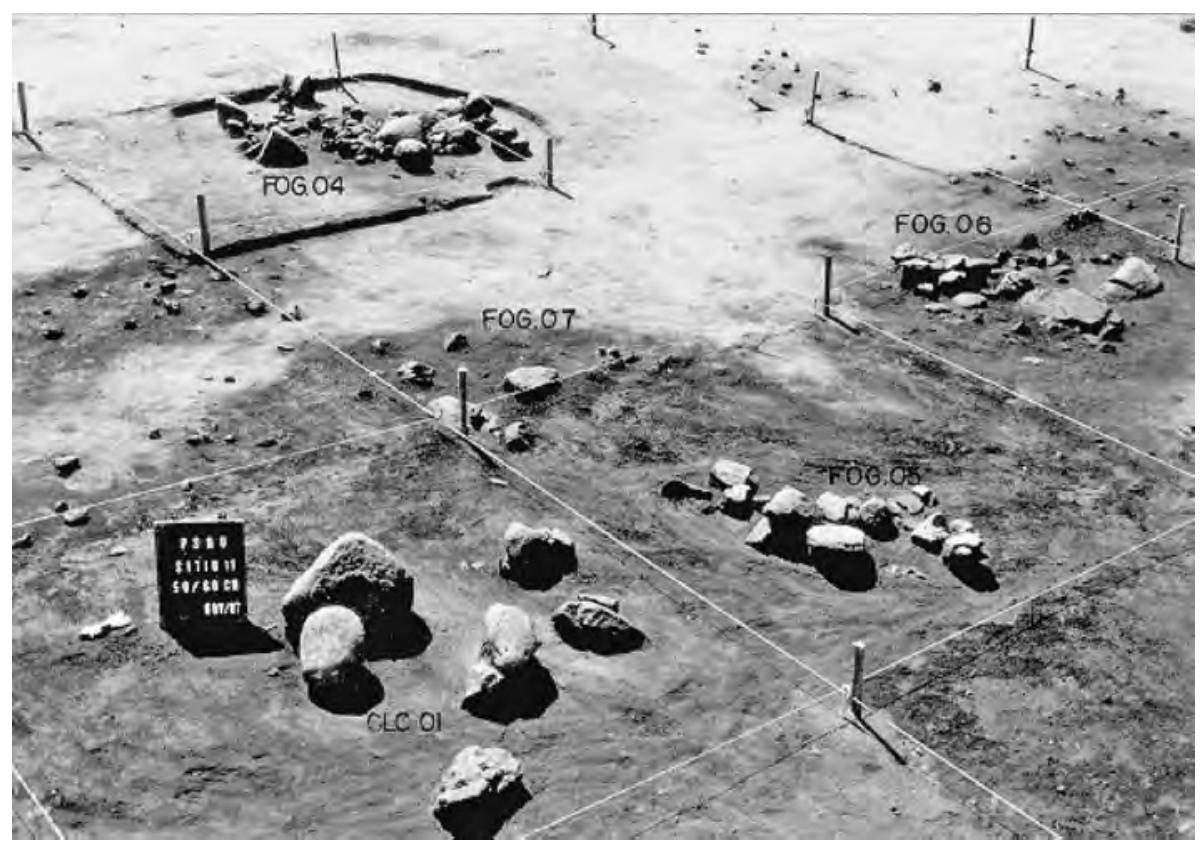

Fig. 10. Escavação evidenciando manchas pretas bem preservadas, frequentes nas pesquisas realizadas no final da década de 1980 e início da década de 1990. Fonte: Goulart (1997a). 


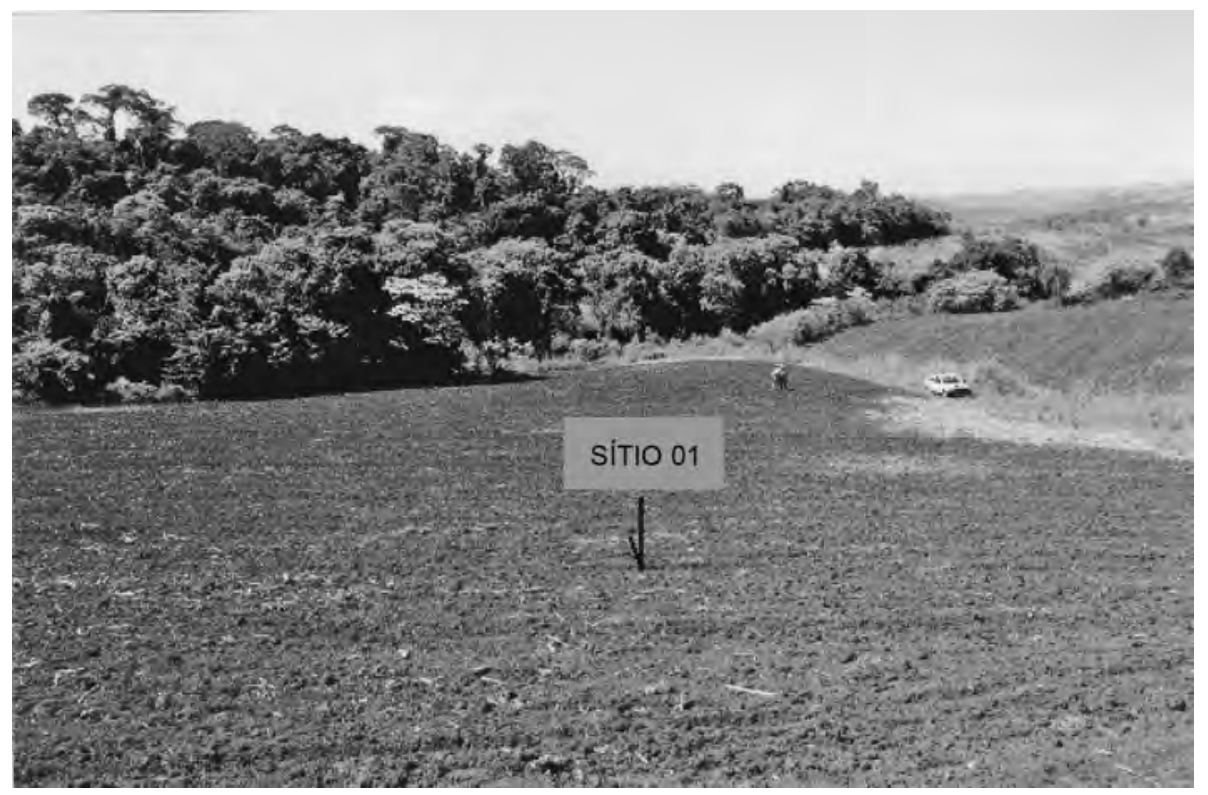

Fig. 11. Área do sítio 01 que apresentava mancha preta em 1989, não identificada na reavaliação dos sítios realizada em 1996. Ao fundo ainda verifica-se o solo levemente escuro, resquícios das manchas pretas. Fonte: Goulart (1997a).

RUBIN, J.C.R; CARBONERA, M. Considerations about the environmental context of the archaeological sites from Upper Uruguay river: Uruguay Archaeological Rescue Project (Itá Hydroelectric Power Plant). R. Museu Arq. Etn., São Paulo, n. 21, p. 153-166, 2011.

Abstract: In this paper we have analyzed the data regarding the environmental aspects and the archaeological sites surveyed during one of the stage from Uruguay Archaeological Rescue Project, held between the 1980's and 1990's. We present some reflections on the dynamics of the area and anthropic action, and how these processes might have altered the sites until the time of their record. We underline the importance of the relativity of the information collected simultaneously to avoid misinterpretations.

Key-words: Upper Uruguay - Archaeological sites - Geoarchaeology.

\section{Referências bibliográficas}

\section{CARBONERA, M}

2008 A tradição Tupiguarani no Alto Uruguai: Estudando o Acervo Marilandi Goulart. Dissertação de Mestrado. São
Leopoldo, Universidade do Vale do Rio dos Sinos.

GOULART, M. (Coord.)

1988a Situação atual das pesquisas arqueológi- 
cas: Barragem de Itá - SC/RS. Florianópolis: UFSC/ELETROSUL.

1988b Síntese da situação atual das pesquisas: Barragem de Itá - SC/RS. Florianópolis: UFSC/ELETROSUL.

1994 Projeto Salvamento Arqueológico Uruguai: UHE Itá. Florianópolis: UNIVALI.

1997a Projeto Salvamento Arqueológico do Uruguai, Volume I, Introdução. Itajaí: UNIVALI.

1997b Projeto Salvamento Arqueológico Uruguai, Volume II, Tomos: I, II, III e IV, Ambiente. Itajaí: UNIVALI.

LEINZ, V.; AMARAL, S.E.

1980 Geologia Geral. São Paulo: Ed. Nacional.

LIMA, M.C.

1999 Contribuições ao estudo do processo evolutivo de boçorocas na área urbana de Manaus. Brasília. Dissertação de Mestrado, Faculdade de Tecnologia/UnB.
NOELLI, F.

1996 Debate: Hipótese sobre a origem e a expansão dos Tupi. Revista de Antropologia, 39: 7-63.

PALLESTRINI, L.

1975 Interpretação das estruturas arqueológicas em sítios do Estado de São Paulo. Coleção do Museu Paulista, 1. Série de Arqueologia. São Paulo: USP.

RICCOMINI C.; GIANNINI, P.C.F.; MANCINI, F.

2001 Rios e processos aluviais. In: Teixeira, W. Toledo, M.C.M.; Fairchild, T.R.; Taioli, F. (Orgs.) Decifrando a Terra. São Paulo: Oficinas de Texto.

RUBIN, J.C.R.; SILVA, R.T.; BARBERI, M.

2003 Arqueologia e a dinâmica da paisagem: pesquisa arqueológica em ambientes fluviais. Revista Habitus, 1 (2): 297-316.

RUBIN, J.C.R.; SILVA, R.T.

2004 Arqueologia, dinâmica das vertentes e perdas de solos. Revista do Museu de Arqueologia e Etnologia, 14: 179-193. 